\title{
Code-switching in Heritage Danish varieties in North America and Argentina: Inventory, frequency and function
}

\author{
JAN HEEGÅRD PETERSEN, KAROLINE KÜHL, AND \\ GERT FOGET HANSEN
}

This paper analyses the lexical influence that Spanish and English have had on Danish as spoken by Danish immigrants and their descendants in Argentina, USA, and the small town New Denmark in the Canadian province New Brunswick. The data come from Corpus of American Danish $(\mathrm{CoAmDa})$, and the research is based on an inventory of 880,668 tokens (words and transcriptions of spoken language phenomena such as hesitation, self-interruption, etc.). The analysis reveals large quantitative differences between the three data sets: The data from USA contain the most non-Danish words, the data from Argentina the least non-Danish words, with the Canadian data somewhere in-between. The data sets also differ significantly from each other with respect to which parts-of-speech are represented among the English and Spanish words. The speakers from Argentina mostly borrow nouns and discourse words from Spanish whereas the speakers from USA borrow English words from all parts-of-speech. Furthermore, the New Denmark speakers show a borrowing pattern in-between the two others. The data also show that the speakers from Argentina to a much higher degree use Spanish words together with meta comments like som vi siger ('as we say'), and that the lexical code-switches to Spanish also often occur in connection with hesitation markers to a higher degree than in the other two data sets. The paper concludes that while the differences in how Danish has been influenced are due to the different macro-sociolinguistic conditions in the three counties, the choice of method (i.e. interview bias) and the typological differences 
between Danish and Spanish and between Danish and English must be taken into consideration.

KEYWORDS: code-switcing; bilingualism; CoAmDa; language contact; spoken language corpus; corpus linguistics 